This item was submitted to Loughborough's Research Repository by the author.

Items in Figshare are protected by copyright, with all rights reserved, unless otherwise indicated.

\title{
Targeting relationally integrated project teams for sustainable PPPs
}

PLEASE CITE THE PUBLISHED VERSION

http://dx.doi.org/10.1108/09699980710829030

PUBLISHER

(C) Emerald

VERSION

AM (Accepted Manuscript)

LICENCE

CC BY-NC-ND 4.0

REPOSITORY RECORD

Kumaraswamy, Mohan M., Florence Y.Y. Ling, Aaron M. Anvuur, and M. Motiar Rahman. 2019. "Targeting Relationally Integrated Project Teams for Sustainable Ppps”. figshare. https://hdl.handle.net/2134/12347. 
This item was submitted to Loughborough's Institutional Repository (https://dspace.lboro.ac.uk/) by the author and is made available under the following Creative Commons Licence conditions.

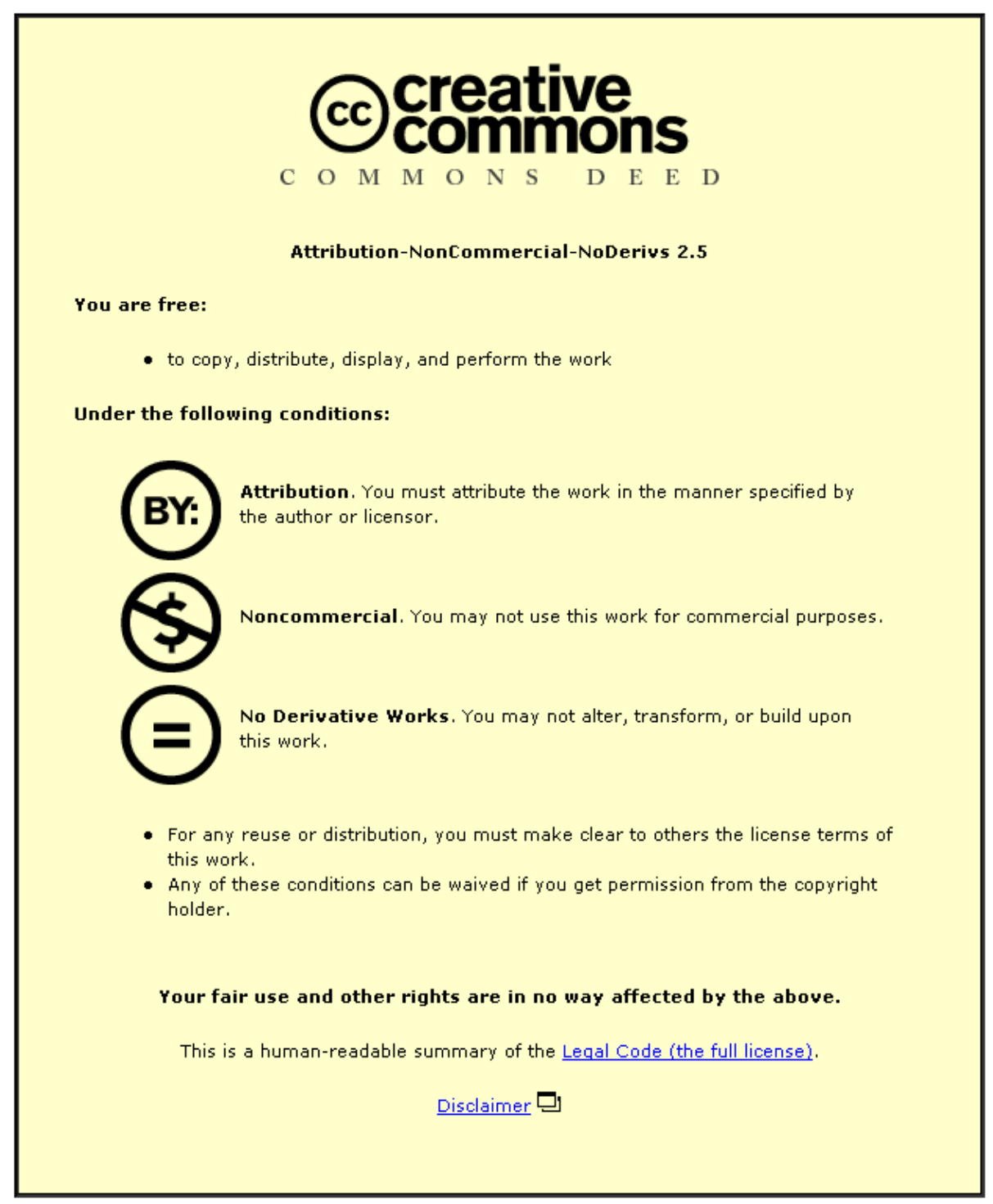

For the full text of this licence, please go to: http://creativecommons.org/licenses/by-nc-nd/2.5/ 


\title{
TARGETING RELATIONALLY INTEGRATED TEAMS FOR SUSTAINABLE PPPS ${ }^{1}$
}

\author{
Mohan M. Kumaraswamy ${ }^{1}$, Florence Y.Y. Ling ${ }^{2}$, Aaron M. Anvuur ${ }^{1}$ \\ and M. Motiar Rahman ${ }^{3}$ \\ ${ }^{1}$ Dept. of Civil Engineering, The University of Hong Kong, Hong Kong SAR, China \\ ${ }^{2}$ National University of Singapore, Singapore \\ ${ }^{3}$ University of Glamorgan, United Kingdom
}

\begin{abstract}
Purpose - This paper targets the development of comprehensive approaches to prequalifying teams for Public Private Partnerships (PPPs).

Approach \& Findings - Research outcomes from a study into 'relationally integrated project teams' (RIPTs) were applied to necessarily longer term PPP scenarios. A force field model was developed to visualise the importance of stronger relational forces between the many PPP participants for 'sustainable RIPTs' (SRITs). A framework was conceptualised to show linkages from relational contracting approaches, through sustainable relationships to sustainable infrastructure. This framework and a basic model for evaluating relational performance were assessed by a panel of international PPP experts. The results encouraged the collection of factors facilitating successful relationships to build the proposed knowledge base. Literature review and initial interviews provide examples of priorities and lessons learned in relationship building in ongoing PPPs.

Research and Paper Limitations - Being an integrative theory-building type exercise bringing together relational contracting, teambuilding and PPP performance research streams, this paper summarises and refers to, rather than provides details of, feeder research. Fleshing out the conceptual framework and model will next proceed beyond the initial testing and sample knowledge elements conveyed herein.

Practical Implications - Selecting good teams is essential for successful projects, and more so for PPP projects, given their complexities and longer timeframes. Increasing reliance on PPPs for infrastructure development and asset management enhances this significance.

Originality/Value - Synergies are derived from linking relationship-building and sustainability thrusts in the context of PPP performance. Concepts of 'sustainable relationships' and 'sustainsivity' (sensitivity to sustainability issues) are introduced.
\end{abstract}

Keywords: PPPs, Prequalification, Sustainability, Team selection, Teamworking.

\section{BACKGROUND AND INTRODUCTION}

The levels of private sector involvement in infrastructure development and indeed in some elements of national developments have escalated in many countries over the past few centuries. As discussed by Jeffries et al. (2006), the 'public vs private debate' has been going on since Adam Smith's the 'Wealth of Nations' in 1776. Some nations have ventured at various times to entrust their socio-economic development, either entirely to

\footnotetext{
${ }^{1}$ This is the pre-publication version of Kumaraswamy, Ling, Anvuur, and Rahman (2007) published in Engineering, Construction and Architectural Management, 14(6), 581 - 596.
} 
the government through the public sector, or sometimes to totally rely on market forces via the private sector. Drawing on both public and private sector resources together has also been possible i.e. through Public Private Partnerships (PPPs), e.g. looking back to the railroads that opened up the West of the USA; or even further back to the ten year concession for commercial exploration of the Guinea Gulf awarded to a sailor by the King of Portugal in the $15^{\text {th }}$ century in exchange for the 'discovery of new lands' (Branco et al., 2006). The popularity of PPPs has fluctuated with the ideologies and needs of the time and place, e.g. since governments must necessarily play a bigger role during both financial and natural crises, as well as during wars and conflicts.

However, the marked interest in PPPs that resurfaced in the last two decades has moved PPPs from their 'first generation' that essentially chased private funds to finance infrastructure development; to the 'second generation' that seeks greater efficiencies and value for money (Duffield, 2005). These efficiencies are expected to result in superior performance levels in creating and managing, and not merely 'maintaining', assets that include not only physical infrastructure such as roads and power stations, but also schools and prisons. Furthermore, those pursuing PPPs must cross dangerous mine fields (Ogunlana, 2005), given the many more variables, risks and lack of experience in dealing with such complex scenarios. Furthermore, the long time frames of most concessions impose extra demands that PPPs should not just be 'successful' but sustainable as well.

Moreover, it is now clear that high performance levels in infrastructure development and management depend, not just on drastically improved structures and systems but, also on enhanced project cultures and integrated teamworking (Construction 21, 1999; CIRC, 2001; Constructing Excellence, 2004). Combining these with the needs for sustainable performance levels in PPPs, as above, these point to the requirement for superior teams who can work well together in the long term, in managing the constructed infrastructure product. This paper therefore applies and adapts findings from research into factors facilitating relationally integrated project teams, to formulate a conceptual framework aimed at developing and sustaining good relationships and performance levels throughout the PPP time frame. Feedback from a group of international PPP experts is summarised to indicate the suitability of the framework and its proposed further development. Furthermore, interviews with PPP players and stakeholders involved in recent and forthcoming PPP initiatives in Hong Kong and Singapore reinforce the value of the proposed approaches to targeting sustainable relationally integrated project teams.

This therefore is essentially a theory-building type paper that develops and presents integrative concepts and frameworks, drawing on both research that is reported in more detail elsewhere, as well as on samples of new evidence being collected, e.g. the samples of factors that can be injected into the proposed knowledge base of relational success factors and sub-factors.

The needs for the above-mentioned integration and consolidated developments are further reinforced by recent research elsewhere. For example, in Australia: (1) Cheung (2006) provides examples of culture change through better relationship management in infrastructure supply chains in general; while (2) Jefferies et al. (2006) target the minimising of transaction costs in the bidding process for PPPs, also aiming at more sustainable procurement. Also in general, (3) Chen et al. (2006) proposed a decision support model to evaluate (a) the 'sustainable performance potential of partner candidates' in terms of environmental consciousness and sustainable performance, as well as (b) the sustainability of such construction partnerships, for construction projects in general. 
Sustainability is clearly more significant in PPPs, given the much longer time horizon, but little detailed work has been as yet done in this direction itself, while it has not been integrated with the other important dimension of 'relationships' for sustainable teambuilding as well.

\section{TEAM-BUILDING IMPERATIVES}

\section{Teamworking and Integration}

Teams are more than mere working groups. They should be groups with complementary skills, a common purpose and are mutually accountable for their achievements, with members being mutually supportive in working together towards their goals (Constructing Excellence, 2004). Teamworking models indicate how teams can work and perform better in general (e.g. Rippin, 2002; Belbin, 2004). However, in the construction industry, increased specialisation over the past century or so, has led to fragmented project teams. More recently, this has been deplored as unproductive (e.g. Latham 1994), because the advantages of specialisation have been overwhelmed by the difficulties of co-ordinating inputs and integrating outputs.

Recognising this problem, exhortations for integrated teams have resonated across the world in the last two decades (e.g. Egan, 1998; ISR, 1999; CIRC, 2001; Constructing Excellence, 2004). Of course there were differences in detailed recommendations, e.g. calls for integrated teams in Singapore, focused more on organisational or 'structural' integration, in terms of linking the functions of design and construction in design \& build contracts. On the other hand, the UK, Australia and Hong Kong Reports recognised the need for what has recently been termed 'relationally integrated teams (Kumaraswamy et al., 2005a), that require more than mere organisational or functional integration of structures and systems.

\section{Building Relationally Integrated Project Teams (RIPTs)}

In the light of the above, selecting suitable teams has been recognised as critical to the success of construction projects in general. To achieve this, there has been a significant shift from the previous 'lowest price wins' paradigm to incorporating non-price criteria in selecting contractors (Kumaraswamy and Walker, 1999) and other supply chain partners (Palaneeswaran et al., 2001) and indeed even more so in PPPs e.g. in selecting BOT concessionaires (Zhang et al., 2002). An increasingly important non-price criterion is the potential for 'relational integration' as discussed in the above paragraph.

Recommendations for 'relational' approaches are (a) reinforced by examples from practice, of successful partnering and alliancing arrangements (Bennett and Jayes, 1998; Hauck et al., 2004); as well as (b) justified in theory, by the benefits of superseding rigid disputegenerating traditional contracts with relational contracting (Macneil, 1974) that can empower joint risk management between partners (Rahman and Kumaraswamy, 2002).

The 'Classical contracting Approaches' (CAs) typical of traditional contracts imply segregated teams, adversarial contracts, a blame culture and a short-term focus; and are in turn blamed for poor performance levels. 'Relational contracting Approaches' (RAs) on the other hand, are expected to generate integrated teams, Joint Risk Management (JRM), sustainable relationships and a longer-term focus. 
Figure 1 is developed to indicate different degrees of 'balance' between force-fields of CAs and RAs, that position team members at appropriate 'distances' apart in general. In particular, Figure 1(a) illustrates how CAs push team members apart (e.g. through 'them vs. us' attitudes) in a two-member scenario, while RAs pull them together (e.g. through close collaboration, shared problems and successes). Figures 1(b) and 1(c) compare the net impacts (of fragmentation and segregation) on a three-member team under dominance of CAs and RAs respectively, where the team members gravitate together as in 1(c), rather than apart as in 1(b).

A general multi-country survey of cross-sections of Australian, Hong Kong, Dutch, Singaporean and UK construction practitioners, unveiled an awareness of the benefits of relational contracting and integrated team working in their projects (Rahman et al., 2005). There was a clear appreciation of the need for relationally integrated project teams (RIPTs) in Singapore as well (Kumaraswamy et al., 2005), although the C21 (1999) Report had previously focused on structural (functional) integration unlike the Australian, UK and Hong Kong Reports that had stressed integrated relationships. For example in Singapore, 27 factors facilitating integrated project teams and 26 factors deterring integrated project teams were found to be significant out of 28 and 31 hypothesised factors respectively (Kumaraswamy et al., 2005a). Such knowledge could be captured and made available when constructing RIPTs in different regions.

RAs harmonise relationships among contracting parties, reducing areas of disagreements and lubricating transactional friction (Rahman and Kumaraswamy 2002). These are achieved by focusing on common objectives, adopting more cooperative approaches (e.g. in partnering), and introducing more conducive and useful mechanisms over and above classical contracting practices and principles (e.g. through JRM), The latter emphasises clear and equitable allocation of all foreseeable risks, along with RC based contract adjustment mechanisms for addressing any unforeseen events and changes during contract execution. Together with such mechanisms, RAs foster cooperation among team members with a longer-term mind-set; and can therefore also focus team efforts on whole-lifecycle performance and sustainability issues in infrastructure provision (Kumaraswamy et al., 2006). The pull (i.e. relational) forces are therefore stronger than the push forces (i.e. RAs > CAs) and so reduce the 'distances' between multiple team members, as shown in Figure 1(c).

\section{Please Insert Figure 1 about here}

Figure 2 extends this concept to larger and more complex PPP teams. It illustrates how the various PPP partners could be drawn together by more dominant integrative forces, to cooperate for mutual long-term benefits with the Project Consortium (PC) which is the 'special purpose vehicle'/ franchisee formed by the private partners. Such multi-functional teams engaged on multi-objective long-term projects would benefit from sustainable relationships and vice versa.

\section{Please Insert Figure 2 about here}

For example, the additional imperatives for asset management, including operation and maintenance, call for a more holistic and sustainable approach from the concept design stage itself. Kumaraswamy et al. (2006) described how the longer time horizon could transform JRM (Joint Risk Management) concerns and efforts into JSRM (Joint Sustainability Risk Management) in order to jointly target asset sustainability. This would 
demand more durable designs including specifications for materials, constructability, environmentally friendly construction methods, better maintainability and operability. Apart from this sustainability of the physical infrastructure assets, the sustainability of the team relationships themselves is the other crucial aspect to be considered in PPPs.

\section{SUSTAINABLE RELATIONALLY INTEGRATED PROJECT TEAMS (SRITs)}

\section{Developing an overall Framework for a SRIT prequalification Model}

Moving from shorter term RIPTs (relationally integrated project teams) in projects (Rahman and Kumaraswamy, 2004), to longer term PPP projects, superimposes additional demands, such as for sustainable relationships and JSRM as noted above, and for what may be summarised as SRITs (sustainable relationally integrated project teams). These further demands call for additional selection criteria in the short-listing of PPP teams e.g. in assessing the potential for sustainable relationships. An example of a possible approach to select SRITs for PPPs was conceptualised and used in a survey of experts in 2005 (Kumaraswamy and Anvuur, 2007). Summarised points from a detailed 10 page description issued along with the questionnaire are presented below.

The proposed PPP team prequalification approach ties performance against (1) 'hard/technical' criteria (2) 'relational' criteria and (3) 'sustainsivity' (sensitivity of key team members to important sustainability issues) criteria, to an integrated framework, along with tools for evaluating such performance. High 'sustainsivity' implies faster and better responses in dealing with sustainability concerns on the project. It is suggested that such an integrated approach offers great synergies and better assurance of sustainable infrastructure. While many short-listing/ prequalification systems have been developed to evaluate against hard/ technical criteria, only a few provide for useful assessments of relational criteria, and even fewer consider sustainability factors.

It should be noted that the hard/ technical criteria include track records of constituent companies and key individuals; as well as resources available for the project. This includes financial capacities, and also possibly, a preliminary proposal on how the consortium would approach this particular PPP project brief.

What is discussed in this paper is for the prequalification (or shortlisting) only. It therefore focuses on team capacities and potential, based on track records etc, and not (at this stage) on other criteria needed for evaluating PPP proposals, e.g., the financial and technical packages actually offered for a given project. The proposed prequalification system would provide for: (a) scoring against important factors under all three categories in the above paragraph, and (b) combining the resulting scores appropriately in a given scenario. The 'relational capability' and 'sustainsivity potential' scores, in addition to performance against hard/ technical criteria, can be stored in continuously updated databanks of public or large private clients to provide information on a viable supply network. Threshold scores defined by the client organisation can determine eligibility. Candidate consortia, who respond to an Expression of Interest (EOI) invitation, may thus be assessed for their eligibility at prequalification stage, by comparing their (1) technical capacity (including financial and other resource capacities), (2) relational capability and (3) ‘sustainsivity'.

The combined score for the past performance of each tenderer is the sum of the weighted scores in the technical, relational and sustainsivity evaluations. Then the Past Performance 
Score, $\mathrm{P}$, of each applicant consortium can be computed as shown in Figure 3 as $\mathrm{W}_{C} \mathrm{C}+$ $\mathrm{W}_{R} \mathrm{R}+\mathrm{W}_{S} \mathrm{~S}$.

$\mathrm{W}_{C}, \mathrm{~W}_{R}$ and $\mathrm{W}_{S}$ are the chosen weightings applied to the technical, relational and sustainsivity score components respectively, as in Figure 3; and $\mathrm{W}_{C}+\mathrm{W}_{R}+\mathrm{W}_{S}=1$.

\section{Please Insert Figure 3 about here}

The weightings would depend on the relative importance of the $\mathrm{C}, \mathrm{R}$ and $\mathrm{S}$ priorities on any given project and should be assigned by the project decision-makers. The unweighted component scores are based on the assessments of each of the applicants. Furthermore, each applicant is assumed to be a consortium of companies including financiers, designers, constructors and operators. The combined 'Team Criteria' scores (e.g. $c_{1} \ldots c_{m}$ and $r_{1} \ldots r_{m}$ ) are therefore, the weighted averages of the technical, relational and sustainsivity scores respectively, of the individual companies constituting the respective applicant consortium, depending on their contributions on the corresponding aspects.

The final Past Performance Scores would be the basis for pre-qualifying consortia that would next be issued formal Requests for Proposals (RFP). Since each prequalified tendering consortium should have the minimal relational capacities, their proposals at this stage could be assessed based on how well they respond to the project specific criteria outlined in the RFP, the price tendered for the range of services required and their proposed value contributions to the development and management of the asset. After the selection of the preferred bidders, structured team building workshops can be organised to promote cooperative interactions between the contracting parties and to align their respective project objectives as in Figure 4. During these workshops, contractual adjustment mechanisms, issue resolution protocols, incentive mechanisms and team interaction protocols can be negotiated. Agreed project objectives comprising technical (e.g. schedule and quality/ performance levels as well as financial and socio-economic), relational (e.g. teamwork and openness) and sustainability (e.g. reducing environmental impact) targets can then be agreed in a Partnering Charter or Alliance Agreement.

The PC (Project Consortium) will be expected to mobilise their various relational strengths to synergistically interact among themselves as well as to co-operate with the rest of the PPP team as in Figure 2, in order to deliver a 'sustainable' infrastructure product as Figure 4. The envisaged joint problem solving initiatives can then be extended to cover both risk and sustainability issues. This integrated approach contributes directly to sustainable infrastructure and indirectly through the longer-term and wider contributions via 'sustainable relationships'. For example, relationship building also leads to 'knowledge-building' of critical success factors that will then be incorporated in the 'knowledge base' in Figure 4. Through this approach, it is expected to focus more attention on increasingly important considerations such as efficient use of resources, supporting desirable natural environments, improving value for money, providing customer satisfaction, facilitating flexibility for user changes and enhancing the quality of life. A focus on these considerations will clearly contribute to more sustainable infrastructure and ultimately, sustainable development as also shown in the overarching broad framework in Figure 4.

\section{Please Insert Figure 4 about here}




\section{Assessing the Framework and proposed SRIT prequalification model}

An example of the proposed operationalisation of the above framework was indicated in a basic model that focused on the relational aspects, and thus included examples of relational factors and sub-factors. These details, with further descriptions, were included in the 10 page document issued for the survey of experts in 2005. These are described by Kumaraswamy and Anvuur (2007), and therefore excluded here in deference to space limitations and the undesirability of repetition.

However, it should be noted that the proposed basic SRIT prequalification model includes examples of relational criteria or factors e.g. (1) values, (2) attitudes; each of which links to a number of interdependent key relational sub-factors e.g. the 'values' factors link to consistency, openness, fairness etc.; and the 'attitudes' factors link to receptivity, commitment, care, readiness for joint decision-making etc. The relational factors may be weighted to reflect different priorities of the project and/or client. Each relational subfactor is then assigned a score of $0,1,2,3$ or 4 representing 'unacceptable', 'below average', 'acceptable', 'good' and 'excellent' respectively. Guidance notes verbalise the interpretation of each point of the Likert scale. The relational score is the sum of the weighted scores earned for each relational sub-factor. This will allow a less subjective comparison of the relational qualities of various potential team players based on measurements of their 'relational capability' on previous projects. A rating system classifies the relational scores into bands/ intervals of 'relational capabilities' defining 'excellent', 'good', 'acceptable', 'below average' or 'unacceptable'. Decision rules, formulated on the basis of a suitable multi-attribute decision-making model can also specify a minimum 'relational capability' required for prequalification, in case a client wishes to only shortlist teams with 'good' relational qualities, whatever their other scores.

Table 1 summarises the consolidated scores given by the 11 expert respondents to the survey, as described by Kumaraswamy and Anvuur (2007). Survey and analysis details are not repeated here due to space limits and also because the present paper focuses more on integrative theory-building, based on a cluster of evidence from feeder studies. It may be noted that the respondents were internationally well experienced in PPPs; with two based in Australia, three in Hong Kong, one in Singapore, one in Thailand and four in the UK; and include engineering, financial, legal and construction experts. The high average scores and broad consensus of the experts encouraged further development of the overall conceptual framework, a basic evaluation model and pilot knowledge bases.

\section{Please insert Table 1 about here}

\section{SUSTAINABLE RELATIONSHIPS: BUILDING UP KNOWLEDGE BASES}

The following provide some examples of how useful knowledge can be collected for expanding and finalising the structure and populating the planned knowledge bases of critical factors and sub-factors, by drawing on recent strategies and experiences in the new waves of PPPs in both developed and developing countries.

\section{Examples of Experiential Knowledge from Singapore}


PPPs are seen as 'part of the Best Sourcing framework' and as 'a long-term partnering relationship' (Singapore Ministry of Finance, 2007). The Public Private Partnership Handbook issued in October 2004, summarises 'key factors in a successful relationship' as (a) mutual respect and understanding, (b) open communication, and (c) recognition of mutual aims. It also summarises 'key factors in the management structure' presumably aiming to convey the importance of relationships, for example: 'the relationship at the senior management level sets the tone of the PPP relationship' and 'clear roles and responsibilities should be set and the staff empowered for the different structures in place to manage the relationship at different levels'.

Eight interviews were conducted with Government officials, legal and financial experts, a PPP Client/ Promoter and three Project Consortium (PC) partners/ potential partners, with two on the 'design \& construction' side and the third on the 'operations \& maintenance' in Nov. 2006 and Jan. 2007. Interviewees indicated the need for accelerating the learning curves and PPP awareness of lower level staff of stakeholders. Some felt that many banks and developers in Singapore were still wary of the PPP model.

Many saw a need for 'champions'/ 'driving' personalities in both public (Client) and private (PC) sector groups of a PPP project team. They could drive the vast changes in mind-sets and working arrangements that were seen to be critical for any PPP success, given the innovative thinking needed.

It was also seen that approaches must change from reactive to proactive e.g., to preventive rather than 'fix-it' in operations management. Interesting examples of benefits from knowledge transfers across functions, disciplines and indeed sectors, were noted and could be used to populate the planned knowledge base. For example, a facilities management team was pleased to have learned some planning and control techniques, including for inventory optimisation, from the CEO of a Client, and were now applying these techniques on other projects, providing an example of effective knowledge transfers.

\section{Examples of Experiential Knowledge from Hong Kong}

In comparison with the above, the introductory guide to PPPs of the Hong Kong SAR Government (Efficiency Unit, 2003) highlights that PPPs: (a) 'are based on a partnership approach, where the responsibility for the delivery of services is shared between the public and private sectors, both of which bring their complementary skills to the enterprise'; and (b) 'PPPs bring together public and private sectors in a long-term relationship', with the private sector moving on to become a 'long-term service provider' rather than a 'simple upfront asset builder'. Furthermore, the handbook highlights relevant objectives such as: (1) 'partnership attitude', 'right skills mix at the right times', and 'desire to make partnership work in practice'; and (2) 'select a private partner that you will be able to work well with throughout the life of the project'. These ideas clearly justify some of the strategies proposed in this paper.

A recent initiative for a mega cultural complex cum property development was studied with a view to learn from the 'false start' initially suffered in this planned PPP. 18 interviews with knowledgeable stakeholders were conducted to identify critical success factors (CSFs) for such projects (Lo, 2006). Potential CSFs were derived from the international literature and the local interviews, and grouped into five elements in a CSF framework. These broad 'elements' are (1) macro environment, (2) Government-Project relationship, (3) Construction-Project relationship, (4) Government-Consortium 
relationship, and (5) Project; and the number of CSFs identified within each element were $8,8,5,7$ and 3 respectively.

It is useful to refer back to Figures 2 and 4 when noting that some of the above CSFs, as identified in the above study supervised by the lead author, involved team-building not just within the PC team, but also with the public stakeholders such as environmental groups. Examples of factors that led to the 'suspension' of the above project were said to include: inadequate communication with stakeholders, inappropriate sharing of skill-sets and risks, lack of protection of public interest, and social opposition. From this it is seen that team-building for PPPs should be approached in a wider context. It should commence up-front with the Client, and involve key stakeholders at the overall project level, before moving into the selection of a 'winning' PC team. In fact the latter could be considered as a key sub-team within the overall PPP project team, as seen in Figure 2.

\section{Examples of Relevant Findings from the UK and in general}

In the context of the above section, it is noted that certain aspects of the importance of team relationships in PPPs, have been appreciated, studied and documented to some extent, in the past. For example, in the UK, Smyth and Edkins (2006) called for a proactive 'relationship management' approach, which they found was needed to replace reactive behavioural adjustments to the new procurement conditions in the PFI/ PPP landscape in the UK.

Also, in the UK, a recent report conveyed the results of a survey of operational PFI projects (including non-construction projects) that covered many aspects (Partnerships UK, 2006). It is relevant that $66 \%$ of public sector respondents rated the performance of these service providers as either 'very good' or 'good'; while $72 \%$ of public sector contract managers rated their relationships with the service providers as either 'very good' or 'good', and $25 \%$ as 'satisfactory'; and $79 \%$ of users were satisfied 'always' or 'almost always' with services received. It is also relevant that, a 'clear correlation' was noted between 'good' or 'very good' relationships and high levels of performance. Although not so strong, a positive link was also discerned between good relationships and user satisfaction. Key factors that influence relationships between public sector and private sector teams were said to include 'communication' (by over 30\% of respondents), trust (20\%), shared objectives (17\%). However, high levels of staff turn over on either side, were one of the factors straining relations.

In general, Pantouvakis and Vandoros (2006) conducted a review of internationally published research in PFI/ PPPs in construction. They found that of 78 PPP journal papers in four selected leading journals over the period 1996-2006, although 42\% were on stakeholder relationships at the contractual level, there had been a shift of interest towards financial management related issues after the late 1990s. It was also noted that the emphasis seems to have been on contractual relationships, which could be more on the structural and legal arrangements, rather than the relational integration which arises from 'relational contracting' type approaches (Kumaraswamy et al., 2005).

The foregoing examples confirm the needs for more relationally integrated as well as sustainable teams in PPPs, and for deeper research to identify the best ways forward in this direction. 


\section{CONCLUDING OBSERVATIONS}

More informed team selection is clearly more critical for sustainable PPPs and the basic prequalification approach proposed here incorporates relational factors into the shortlisting process. While previous research justifies evaluating relational capabilites, the overview in this paper highlights a need to integrate this relationship dimension with considerations of technical competence and sustainsivity (sensitivity to sustainability issues). This paper also develops an integrated conceptual framework, while drawing on findings from the teambuilding, relational contracting and PPP performance research streams, which include previous contributions from these authors.

For example, while KPIs (Key Performance Indicators) and related assessment tools for evaluating technical competence have been developed over many decades, sustainability KPIs are being focused upon in many regions in the last few years (e.g. Ugwu et al., 2006). 'Relationally integrating' factors for construction project teams have been identified from the literature and the reported multi-country survey. Applying and adapting selected relational factors along a PPP timeline, as piloted in the proposed model, was seen to be useful by the surveyed experts. Further examples may be drawn from the tools developed by Cheung et al. (2006) to assess the 'degree of relationalism' of relational contracts in construction through a 'relational index'. Fresh approaches would of course be needed to adapt and apply such methods to the evaluation of the 'strengths' of actual relationships, which would have many dimensions.

Further development of this prequalification model is envisaged along the relational, as well as sustainability dimensions, whereas knowledge bases abound for 'technical' evaluation. The proposed model can be next integrated with the overall PPP team selection system that would incorporate the evaluation of proposals from prequalified consortia that will include assessments of financial and infrastructure operational proposals as well.

Examples of PPP teambuilding exercises and the importance ascribed to teamworking criteria in Hong Kong and Singapore indicate how the proposed knowledge bases may be built up. Also, the overall framework presented in this paper indicates how relational contracting approaches and sustainable relationships can contribute to more sustainable infrastructure and, in turn, to suitably integrated long term development. While PPPs can be valuable in mobilising and synergising such forces, it must be noted that PPPs are certainly not appropriate for all scenarios. Parallel research initiatives (e.g. Anvuur and Kumaraswamy, 2006) are directed at developing decision support for distinguishing scenarios that are suited for PPPs, and indeed for different types of PPPs. Taken together these initiatives will help in deciding where PPP can yield better value overall, and help in selecting better and more sustainable PPP teams that can help increase such value.

\section{ACKNOWLEDGEMENTS}

Grant HKU 7138/ 05E from the Hong Kong Research Grants Council, as well as the Universitas 21 Fellowship received by the lead author, are acknowledged for assisting in this research, while the questionnaire respondents and interviewees are thanked for sharing their valued knowledge.

\section{REFERENCES}


Anvuur, A. and Kumaraswamy, M.M. (2006). Making PPPs work in developing countries: major issues and challenges, CIB W107 Construction in Developing Economies Intnl. Symposium, 18-20 Jan. 2006, Santiago, Chile, CD Rom 10 p.

Belbin, R. M. (2004) Management Teams - why they succeed or fail, 2nd edition, Elsevier Butterworth-Heinemann, Amsterdam.

Bennett, J and Jayes, S (1998). The seven pillars of partnering: A guide to second generation partnering, Reading Construction Forum: Thomas Telford.

Branco, F., Ferreira, J. and Branco, M. (2006). Specifications to achieve Quality in B.O.T. projects, CIB W107 Construction in Developing Economies Intnl. Symposium, 18-20 Jan. 2006, Santiago, Chile, CD Rom 10 p.

Chen, Z., Li, H., Kong, S.C.W. and Xu, Q. (2006). A Decision Support Model for Partner selection in Sustainable Construction, BEAR Conference, Hong Kong, Apr. 2006, CD Rom, 10 p.

Cheung, S.O. (2006). How Relational are Relational Contracts?, Jnl. of Professional Issues in Engineering Education \& Practice, Legal Affairs Section, ASCE, 132(1), 48-56.

Cheung, Y.K.F. (2006). Supply Chain Sustainability - The Role of Trust and Relationship, Conference on Construction Culture, Innovation \& Management, Dubai, 26-29 Nov., British Univ. in Dubai, 710-719.

CIRC (2001). Construction Industry Review Committee Report, HKSAR Govt., HK.

Constructing Excellence (2004). Strategic Forum sets new targets for change, 9/15/2002, http://www.constructingexcellence.org.uk (accessed 20/06/2006).

Construction 21 (1999). Reinventing Construction, Ministry of Manpower and Ministry of National Development, Singapore.

Duffield, C.F. (2005) PPPs in Australia, 'Public Private Partnerships - Opportunities and Challenges', Conf. Proceedings, 22 Feb., CICID, The University of Hong Kong, 5-14.

Efficiency Unit (2003). Serving the Community - by using the Private Sector, Govt. of the HKSAR, $70 \mathrm{p}$.

Egan, J. (1998). Rethinking Construction, HMSO, London, UK.

Hauck, A.J., Walker, D.H.T., Hampson, K.D. and Peters, R.J. (2004). Project Alliancing at National Museum of Australia - Collaborative Process, Journal of Construction Engineering and Management, 130(1), 143-152.

Jefferies, M.C., McGeorge, D., Chen, S.E. and Cadman, K. (2006). Sustainable Procurement: A contemporary View on Australian Public Private Partnerships (PPPs) Conference on Construction Culture, Innovation \& Management, Dubai, 26-29 Nov., British Univ. in Dubai, 556-564.

ISR (1999). Building for Growth - An analysis of Australian Building and Construction Industries, ISR (Dept. of Industry, Science and Resources), Canberra.

Latham (1994) Constructing the Team, HMSO, London, UK.

Kumaraswamy. M.M. and Anvuur, A.M. (2007) Selecting Sustainable Teams for PPP projects. Building \& Environment, 43(6), 999-1009.

Kumaraswamy, M.M. and Walker, D.H.T. (1999). Multiple performance criteria for evaluating construction contractors' Chapter, in book 'Procurement systems in construction: A guide to best practice in construction, CIB W92, editors: S. Rowlinson \& P. McDermott, Routledge, UK.

Kumaraswamy, M.M., Ling, F.Y.Y., Rahman, M.M. and Phng, S.T. (2005a) 'Constructing Relationally Integrated Teams', ASCE Journal of Construction Engineering and Management, Oct.,131(10), 1076-1086.

Kumaraswamy, M.M., Ugwu, O.O., Rahman, M.M., Ekambaram, P., and Ng, T.S.T. (2006) Relational Contracting for Sustainable Infrastructure, Conf. on 'Built Environment Sustainability in the New Economy', Hong Kong, HKU SPACE, 88-95. 
Lo, C.M. (2006). Critical Success Factors for Public Private Partnerships at West Kowloon Cultural District Project, unpublished Final Year Project Report, Dept. of Civil Engineering, The University of Hong Kong.

Macneil, I.R. (1974). The Many Futures of Contracts, Southern California Law Review, 47, (3), 691-816.

Ministry of Finance (2007). Public Private Partnerships http://www.mof.gov.sg/policies/ppp.html, accessed on Jan. 19, 2007

Ogunlana, S. (2005). Investment in PPPs: Gold Digging in partially cleared minefields, ppt presentation at Conf. on Public Private Partnerships - Opportunities and Challenges, 22 Feb. 2005, Hong Kong, CICID, HKU, http://www.hku.hk/cicid

Palaneeswaran, E., Kumaraswamy, M.M. and Zhang X.Q. (2001). Reforging construction supply chains: A source selection perspective, European Journal of Purchasing \& Supply Management, 7(3), 165-178.

Pantouvakis, J.P. and Vandoros, N. (2006). A Critical Review of Published Research on PFI/PPPs in Construction, CIB W92 Conference Proceedings, Salford, Nov. 2006, pp. 410-419.

Partnerships UK (2006). Operational PFI Projects, Report, March 2006, UK, 127 p.

Phua, F.T.T. and Rowlinson, S. (2004). How important is co-operation to construction project success? A grounded empirical quantification, Engineering, Construction \& Architectural Management, 11(1), 45-54.

Rahman, M.M., and Kumaraswamy, M.M. (2002). Joint Risk Management through Transactionally efficient Relational Contracting, Construction Management \& Economics, 20(1), 45-54.

Rahman, M.M. and Kumaraswamy, M.M. (2004) Potential for Implementing Relational Contracting and Joint Risk Management', Journal of Management in Engineering, ASCE, Oct., 20(4), 178-189.

Rahman, M.M., Kumaraswamy, M.M., Karim, K., Ang, G. and Dulaimi, M. (2005) 'Cross-country perspectives on integrating Construction Project Teams', $6^{\text {th }}$ Construction Specialty Conference of the CSCE, 2-4 June, 2005, Toronto, Canada CDROM, 10 p.

Rippin, A. (2002) Teamworking, Capstone Publishing, Oxford, UK.

Smyth, H. and Edkins, A.J. (2006). Relationship Management in the management of PFI/PPP Projects in the UK, International Jnl. of Project Management, 25, 232-240.

Ugwu, O.O., Kumaraswamy M.M., Wong A., Ng, S.T. (2006). Sustainability appraisal in infrastructure projects (SUSAIP): Part 1. Development of indicators and computational methods, Automation in Construction, 15(2), 239-251.

Zhang X.Q., Kumaraswamy, M.M., Palaneeswaran, E. and Zheng, W. (2002). Concessionaire selection of BOT Tunnel projects in Hong Kong, ASCE Journal of Construction Engineering and Management, 128(2), Mar. / Apr. 2002, 155-163. 
Table 1: Consolidated Assessment Scores of Experts

\begin{tabular}{|c|c|c|c|}
\hline \multicolumn{2}{|r|}{ Criterion } & \multirow{2}{*}{$\begin{array}{l}\text { Average } \\
\text { score* }\end{array}$} & \multirow{2}{*}{$\begin{array}{l}\text { Standard } \\
\text { deviation }\end{array}$} \\
\hline Number & Description & & \\
\hline \multicolumn{4}{|c|}{$\begin{array}{l}\text { Assessment of overall framework that incorporates } \\
\text { relational, technical and sustainability factors for } \\
\text { sustainable infrastructure }\end{array}$} \\
\hline 01 & Clarity & 3.82 & 0.87 \\
\hline 02 & Validity in reflecting real needs & 3.64 & 0.92 \\
\hline 03 & $\begin{array}{l}\text { General coverage of macro-level critical } \\
\text { performance factors }\end{array}$ & 3.45 & 0.69 \\
\hline 04 & Applicability & 3.36 & 1.21 \\
\hline 05 & Adaptability to different scenarios & 3.64 & 0.92 \\
\hline 06 & Potential reliability after expansion & 3.11 & 1.05 \\
\hline 07 & Suitability for further development & 4.20 & 0.79 \\
\hline \multicolumn{4}{|c|}{$\begin{array}{l}\text { Assessment of basic model for evaluating relational } \\
\text { performance }\end{array}$} \\
\hline 08 & Coverage of relational factors & 3.73 & 0.65 \\
\hline 09 & Coverage of relational sub-factors & 3.82 & 0.60 \\
\hline 10 & Potential reliability after expansion & 3.13 & 0.99 \\
\hline 11 & Suitability for further development & 4.00 & 1.00 \\
\hline
\end{tabular}




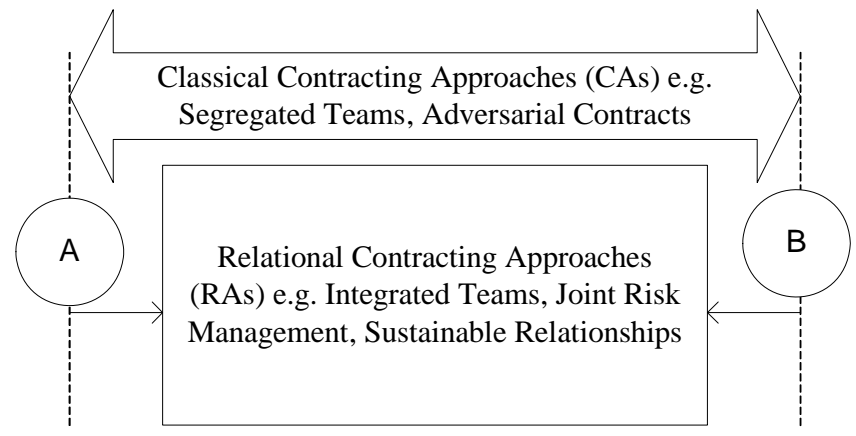

1(a) Equilibrium of Push-pull forces between any two team members

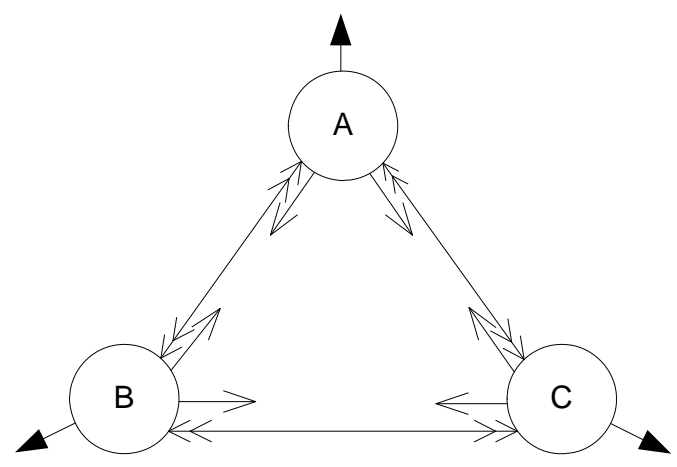

1(b) Fragmenting (segregating) 3-member teams where CAs > RAs

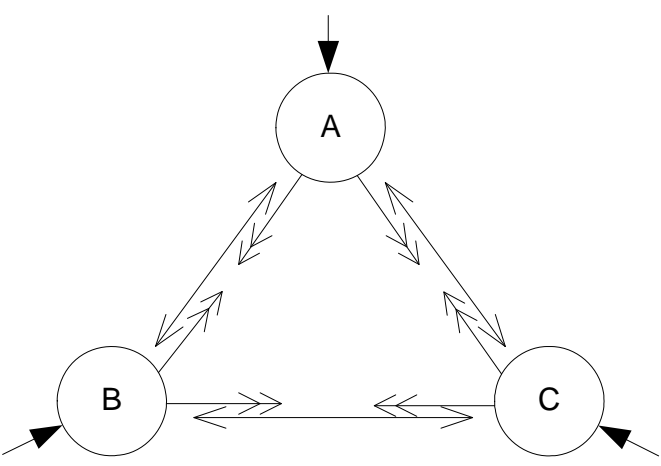

1(c) Relationally Integrating 3-member teams where RAs > CAs

$\begin{array}{ll}\longrightarrow \text { Dominant Force } & \longrightarrow \text { Less Dominant Force } \\ \longrightarrow \text { RAs } \leftarrow & \longleftrightarrow \text { CAs } \longrightarrow\end{array}$

Figure 1: Reducing Team member 'distance' in general 


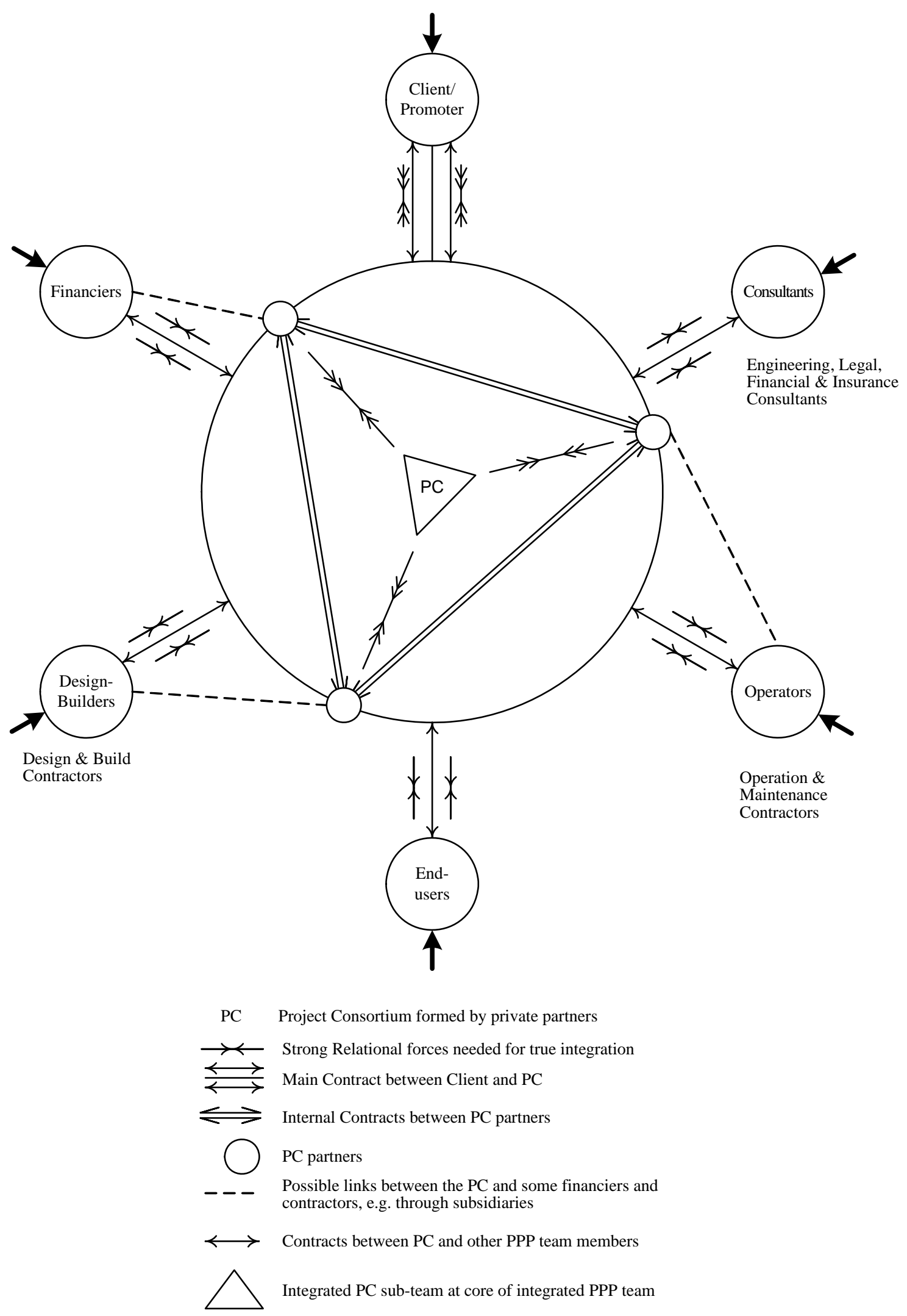

Figure 2: Targeting Relational Integration in PPP Teams 


$\begin{array}{lll}\text { Combined 'Team } & & \text { 'Consortium } \\ \text { Criteria Scores' } \\ \left(\mathbf{c}_{1} \ldots \mathbf{c}_{\mathrm{m}}, \mathbf{r}_{1} \ldots \mathbf{r}_{\mathrm{n}},\right. \\ \left.\text { and } \mathbf{s}_{1} \ldots \mathbf{s}_{\mathrm{p}}\right)\end{array} \longrightarrow \begin{aligned} & \text { Prequalification } \\ & \text { Score' * Components } \\ & \text { (C, R and S) }\end{aligned} \quad \begin{aligned} & \text { 'Consortium } \\ & \text { Prequalification } \\ & \text { Score'* }\end{aligned}$

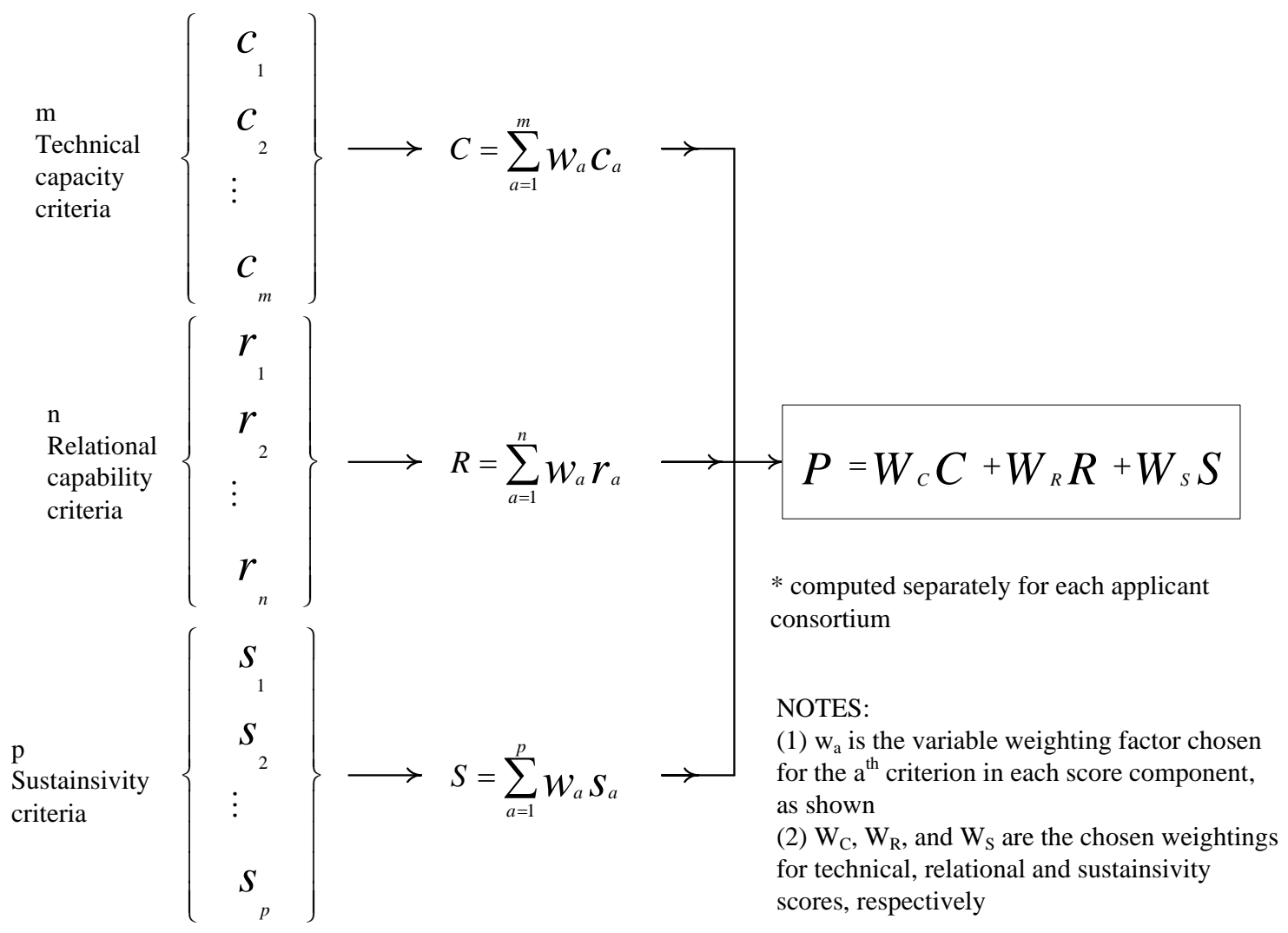

Figure 3: Structuring the compilation of a consolidated Prequalification Score 


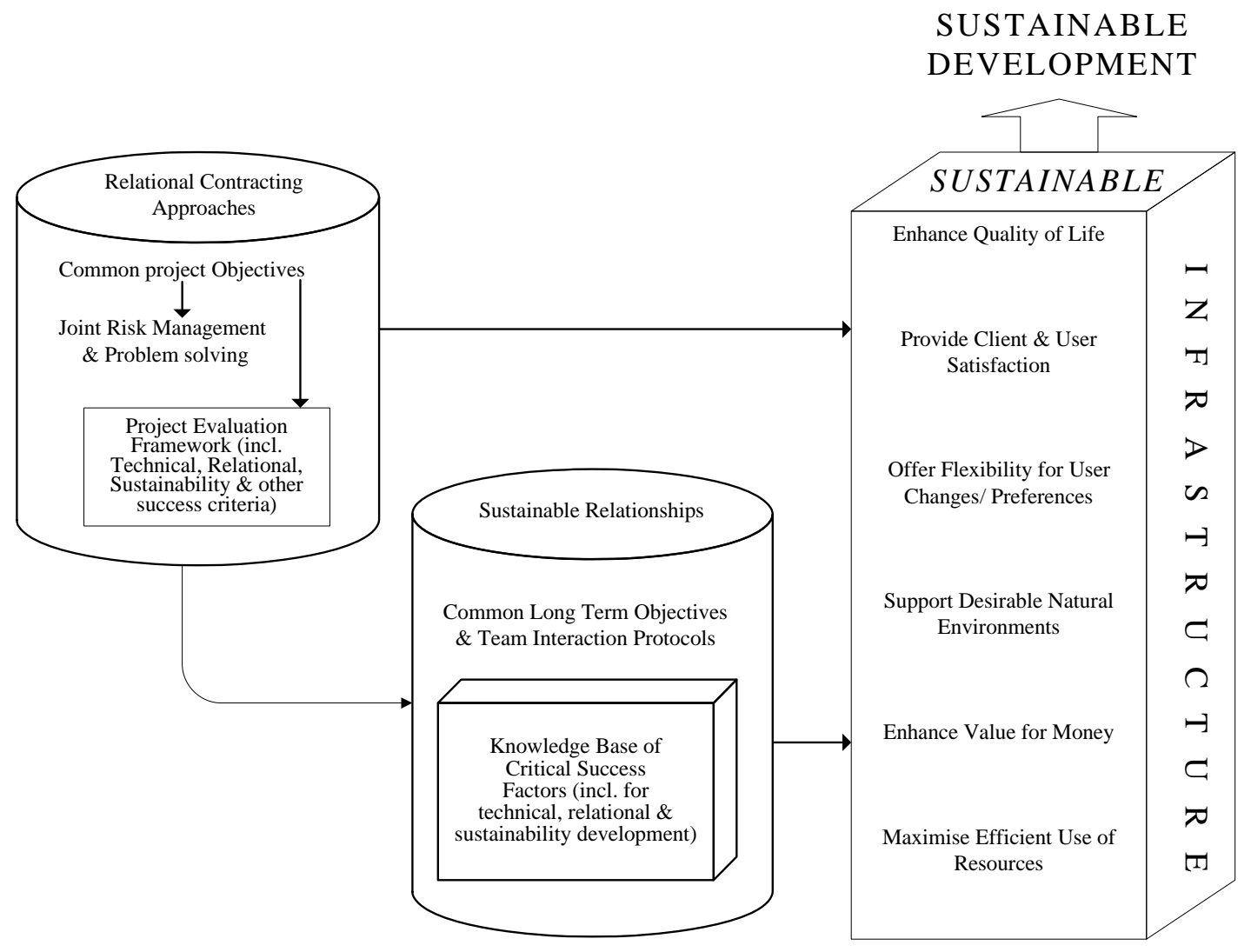

Figure 4: Framework for mobilising Relational Contracting approaches and Sustainable Relationships in Sustainable Infrastructure Development 